\title{
Difference in Cerebral and Hepatic Oxygenation in Response to Ultrafiltration in a Hemodialysis Patient With Congestive Heart Failure
}

\author{
Yuko Mutsuyoshi $^{1}$, Kiyonori Ito ${ }^{1}$, Susumu Ookawara ${ }^{1}$, Takayuki Uchida ${ }^{2}$, Yoshiyuki Morishita ${ }^{1}$
}

1. Division of Nephrology, First Department of Integrated Medicine, Jichi Medical University Saitama Medical Center, Saitama, JPN 2. Department of Clinical Engineering, Jichi Medical University Saitama Medical Center, Saitama, JPN

Corresponding author: Susumu Ookawara, su-ooka@hb.tp1.jp

\begin{abstract}
Near-infrared spectroscopy has been used to measure regional oxygen saturation $\left(\mathrm{rSO}_{2}\right)$, and intradialytic tissue $\mathrm{rSO}_{2}$ measurements have been playing an important role in evaluating changes in tissue oxygenation

in various clinical settings of hemodialysis (HD) therapy. However, few reports have described changes in hepatic oxygenation associated with body fluid management in overhydrated HD patients. We herein report an HD patient with congestive heart failure (CHF) that had improved systemic and tissue oxygenation, including in the brain and liver, during HD with ultrafiltration. A 73-year-old man undergoing HD was admitted to our hospital with CHF. After admission, HD with ultrafiltration was performed to adequately manage his body fluid excess. Because of deterioration of systemic oxygenation on admission, we monitored his percutaneous arterial oxygen saturation $\left(\mathrm{SpO}_{2}\right)$ using a pulse oximeter and regional oxygen saturation $\left(\mathrm{rSO}_{2}\right)$ in the brain and liver using an INVOS 5100c oxygen saturation monitor during HD. At HD initiation, his cerebral and hepatic $\mathrm{rSO}_{2}$ levels were relatively low, at $43.2 \%$ and $34.1 \%$, respectively, in addition to the $\mathrm{SpO}_{2}$ of $88 \%$. During $\mathrm{HD}$ with ultrafiltration, systemic oxygenation evaluated by $\mathrm{SpO}_{2}$ and tissue oxygenation by cerebral and hepatic $\mathrm{rSO}_{2}$ improved. Interestingly, the hepatic $\mathrm{rSO}_{2}$ ratio, defined as the ratio of $\mathrm{rSO}_{2}$ values at $t(\mathrm{~min})$ during $\mathrm{HD}$ and the initial $\mathrm{rSO}_{2}$ value before $\mathrm{HD}$, increased larger than the cerebral $\mathrm{rSO}_{2}$ ratio during $\mathrm{HD}$. After the adjustment of body fluid condition under the maintained $\mathrm{SpO}_{2}$ values, we confirmed the hepatic and cerebral $\mathrm{SO}_{2}$ ratio again during $\mathrm{HD}$, and these two values changed nearly in the same manner. Throughout our experience, in this case, we confirmed a remarkable increase in hepatic $\mathrm{rSO}_{2}$ ratio relative to cerebral $\mathrm{rSO}_{2}$ ratio under a CHF status during $\mathrm{HD}$, and these differences disappeared after the adjustment of the body fluid status.
\end{abstract}

Review began 01/18/2021 Review ended 01/25/2021 Published 01/30/2021

\section{(๑) Copyright 2021}

Mutsuyoshi et al. This is an open access article distributed under the terms of the Creative Commons Attribution License CC-BY 4.0., which permits unrestricted use, distribution, and reproduction in any medium, provided the original author and source are credited.
Categories: Emergency Medicine, Nephrology

Keywords: cerebral oxygenation, congestive heart failure, hemodialysis, hepatic oxygenation, regional oxygen saturation

\section{Introduction}

Cardiovascular disease is known as one of the major complications in chronic kidney disease (CKD) patients, including those on hemodialysis (HD). Its prevalence has been affected by multiple factors, including body fluid excess, hypertension, anemia, and mineral bone disorder [1]. In addition, heart failure was reportedly the most important cause of death in patients on HD [2]. Therefore, adequate body fluid management is necessary to prevent the onset of cardiovascular disease, including congestive heart failure (CHF), and to improve patient prognosis [3,4].

Near-infrared spectroscopy has been used to measure regional oxygen saturation (rSO2), and intradialytic tissue rSO2 measurements, including those of the brain and liver, have been playing an important role in evaluating changes in tissue oxygenation in various clinical settings of HD therapy. Thus far, it has been reported that cerebral rSO2 is low at the onset of acute CHF and improves throughout the management of body fluid excess during HD with ultrafiltration [5], although cerebral and hepatic rSO2 were maintained during HD without intradialytic hypotension $[6,7]$. However, few reports have described changes in hepatic oxygenation associated with body fluid management in overhydrated HD patients. In this paper, we report an HD patient with CHF that had improved systemic and tissue oxygenation, including in the brain and liver, during HD. Furthermore, the relative increase in hepatic rSO2 might be larger than that in cerebral rSO2 in response to the improvement of body fluid status induced by ultrafiltration during HD.

\section{Case Presentation}

A 73-year-old man undergoing HD was referred to our hospital because of chest discomfort and dyspnea. His medical history included hypertension, diabetes mellitus, and myocardial infarction. At the time of referral, his body weight increased by $4.6 \mathrm{~kg}$, which was nearly equivalent to $10 \%$ of his body weight, from the end of 


\section{Cureus}

the last HD therapy two days ago. Furthermore, his chest radiograph showed perihilar vascular engorgement, and he was diagnosed with acute CHF due to excess body fluid. After admission, HD with ultrafiltration was performed to adequately manage his body fluid excess. Table 1 shows the vital signs, laboratory findings, and systemic oxygenation status before HD.

\begin{tabular}{|c|c|c|}
\hline & First measurement (on admission) & Second measurement (4th hospital day) \\
\hline Oxygen inhalation status & $\mathrm{NPPV}$ with $\mathrm{FIO}_{2}$ of 0.6 & Room air \\
\hline \multicolumn{3}{|c|}{ Hemodialysis- associated parameters } \\
\hline Blood Pressure (mmHg) & $104 / 54$ & $121 / 65$ \\
\hline Pulse Rate (beats/min) & 117 & 84 \\
\hline Body Weight (Kg) & 50.9 & 48.6 \\
\hline Ultrafiltration (L/session) & 1.3 & 2.2 \\
\hline \multicolumn{3}{|l|}{ Laboratory findings } \\
\hline Hemoglobin (g/dL) & 12.1 & 10.2 \\
\hline Total protein (g/dL) & 6.3 & 5.9 \\
\hline Serum albumin (g/dL) & 3.6 & 3.3 \\
\hline Blood urea nitrogen $(\mathrm{mg} / \mathrm{dL})$ & 72 & 40 \\
\hline Serum creatinine (mg/dL) & 10.9 & 9.2 \\
\hline \multicolumn{3}{|c|}{ Parameters in systemic and tissue oxygenation } \\
\hline $\mathrm{SpO}_{2}(\%)$ & 88 & 97 \\
\hline $\mathrm{Cerebral} \mathrm{rSO}_{2}(\%)$ & 43.2 & 46.7 \\
\hline Hepatic $\mathrm{rSO}_{2}(\%)$ & 34.1 & 36.7 \\
\hline
\end{tabular}

TABLE 1: Vital signs, laboratory findings, and oxygenation status at first and second measurement of systemic and tissue oxygenation before hemodialysis

This patient provided informed consent before evaluation, and we monitored his percutaneous arterial oxygen saturation (SpO2) using a pulse oximeter (PULSOX-Me300; Teijin Pharma, Tokyo, Japan) and rSO2 in the brain and liver using an INVOS 5100c oxygen saturation monitor during HD. At HD initiation, cerebral and hepatic rSO2 levels were $43.2 \%$ and $34.1 \%$, respectively, in addition to the SpO2 of $88 \%$, even with the use of noninvasive positive pressure ventilation with oxygen administration. Throughout this HD procedure, systemic oxygenation evaluated by $\mathrm{SpO} 2$ and tissue oxygenation by cerebral and hepatic rSO2 improved (Figure 1a), and respiratory management using noninvasive positive pressure ventilation was able to be completed at the end of HD. Interestingly, the hepatic rSO2 ratio, which was defined as the ratio of rSO2 values at $\mathrm{t}(\mathrm{min})$ during $\mathrm{HD}$ and the initial $\mathrm{rSO} 2$ value before $\mathrm{HD}$, increased larger than the cerebral $\mathrm{rSO} 2$ ratio during $\mathrm{HD}$ (Figure 1a). On the 4 th hospital day without his respiratory symptoms under the maintained SpO2 values, we again confirmed the hepatic and cerebral SO2 ratio during HD. Before HD without oxygen inhalation, cerebral and hepatic rSO2 levels were $46.7 \%$ and $36.7 \%$, respectively (Table 1 ). Furthermore, values in cerebral and hepatic $\mathrm{rSO} 2$ were changed nearly in the same manner throughout the HD procedure (Figure $1 b$ ), in contrast to changes in those during HD with an overhydrated status. 


\section{Cureus}

$1 \mathrm{a}$

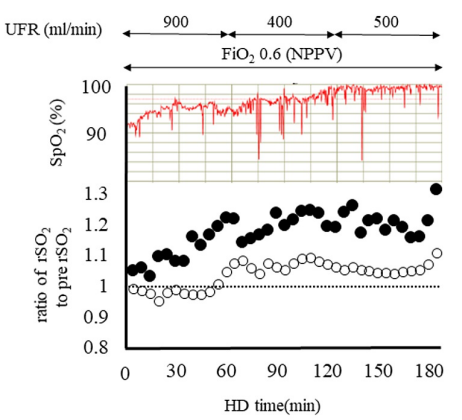

$1 \mathrm{~b}$

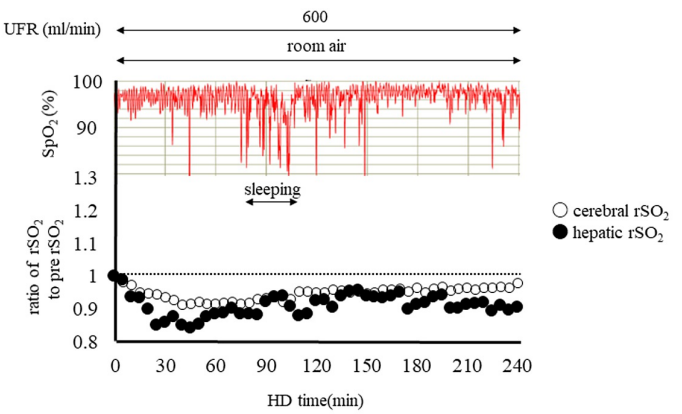

FIGURE 1: Changes in SpO2, and cerebral and hepatic rSO2 during HD

1a: under a CHF status with NPPV, 1b: under stable HD in room air; $\mathrm{SpO} 2$, saturation of percutaneous oxygen; rSO2, regional saturation of oxygen; HD, hemodialysis; CHF, congestive heart failure; NPPV, noninvasive positive-pressure ventilation; UFR, ultrafiltration; FiO2, fraction of inspiratory oxygen

\section{Discussion}

The progression of CKD has been associated with several major complications. Cardiovascular disease, including heart failure, is a major complication induced by excess sodium with fluid retention; its prevalence and severity also increase from early stage CKD to end-stage renal disease [1]. Indeed, heart failure was the most common cause of death (23.5\%) in all-cause deaths in dialysis patients [2]. Therefore, in the field of HD therapy, it is important to adequately manage patients' body fluid status to prevent the prevalence of heart failure [3,4]. However, the causes of heart failure are known to be multifactorial [1]; therefore, it may be hard to completely prevent the onset of CHF in the clinical setting of HD therapy. Thus far, reports regarding tissue oxygenation, including the brain and liver, in patients with CHF and on HD have been limited. A review of the data and findings in previous reports of acute phase CHF and changes in tissue oxygenation are summarized in Table $2[5,8,9]$. 


\begin{tabular}{|c|c|c|c|c|c|c|c|c|}
\hline Authors & Year & $\begin{array}{l}\text { Dialysis } \\
\text { therapy }\end{array}$ & $\begin{array}{l}\text { Number } \\
\text { of } \\
\text { patients }\end{array}$ & $\begin{array}{l}\text { Monitoring } \\
\text { area }\end{array}$ & $\begin{array}{l}\mathrm{rSO}_{2} \\
(\%) \\
\text { at } \\
\text { onset } \\
\text { of } \\
\mathrm{CHF}\end{array}$ & $\begin{array}{l}\mathrm{rSO}_{2}(\%) \\
\text { after CHF } \\
\text { treatment }\end{array}$ & $\begin{array}{l}\text { Main results about tissue oxygenation during } \\
\text { CHF treatment }\end{array}$ & reference \\
\hline $\begin{array}{l}\text { Madsen } \\
\text { PL, et } \\
\text { al. }\end{array}$ & 2000 & No & 9 & Brain & 34 & 50 & $\begin{array}{l}\text { Cerebral oxygen saturation is low at onset of } \\
\text { CHF and increases with the well-being of the } \\
\text { patient by the successful treatment. }\end{array}$ & [8] \\
\hline $\begin{array}{l}\text { Hogan } \\
\text { CJ, et } \\
\text { al. }\end{array}$ & 2011 & No & $\begin{array}{l}19 \text { (non- } \\
\text { adverse } \\
\text { outcome) } \\
33 \\
\text { (adverse } \\
\text { outcome*) }\end{array}$ & $\begin{array}{l}\text { Hypothenar } \\
\text { region of } \\
\text { the palm }\end{array}$ & 57.6 & 66.3 & $\begin{array}{l}\text { Tissue oxygenation increased during } \\
\text { treatment in CHF patients without future } \\
\text { adverse outcomes. However, it was } \\
\text { unchanged for those who later died or were } \\
\text { readmitted. Lack of tissue oxygenation } \\
\text { improvement maybe associated with higher } \\
\text { rates of death and readmission. }\end{array}$ & [9] \\
\hline \multirow[t]{2}{*}{$\begin{array}{l}\text { Minato } \\
\mathrm{S} \text {, et al. }\end{array}$} & \multirow[t]{2}{*}{2019} & \multirow[t]{2}{*}{ HD } & \multirow[t]{2}{*}{1} & & $\begin{array}{l}\text { NPPV } \\
\text { with } \\
\mathrm{FiO}_{2} \\
\text { of } 0.4\end{array}$ & Room air & \multirow[t]{2}{*}{$\begin{array}{l}\text { Cerebral oxygenation deteriorated with the } \\
\text { CHF status but was improved by body-fluid } \\
\text { management during HD. }\end{array}$} & \multirow[t]{2}{*}{ [5] } \\
\hline & & & & Brain & 34 & 45 & & \\
\hline
\end{tabular}

TABLE 2: Changes in tissue oxygenation throughout the treatment of congestive heart failure

Only three reports were found, which discussed the association between them. Two out of the three reports did not include patients with dialysis therapy [8,9] and only one case report was for an HD patient [5]. Tissue oxygenation was measured at the forehead [5,8] and hypothenar [9] and improved after CHF treatment in all reports. Particularly, ultrafiltration during HD had a positive effect on cerebral oxygenation [5] and lack of tissue oxygenation improvement might be associated with higher rates of death and readmission [9].

In HD patients without intradialytic hypotension, cerebral and hepatic rSO2 at HD initiation were $46.5 \pm$ $1.3 \%$ and $52.4 \pm 1.7 \%$, respectively [7]. Furthermore, these rSO2 values were relatively constant despite ultrafiltration and cerebral rSO2 values were significantly lower than hepatic rSO2, which might be a specific feature of tissue oxygenation in HD patients without excess body fluid [7]. Recently, in a patient with acute $\mathrm{CHF}$ on $\mathrm{HD}$, cerebral rSO2 reportedly increased during $\mathrm{HD}$ with ultrafiltration according to the systemic oxygenation increase [5]. This increase in cerebral rSO2 might have originated from the improvement of cerebral microcirculation associated with body fluid adjustment, in addition to the improvement of systemic oxygenation. Therefore, the increase in cerebral rSO2 in response to the improvement in body fluid status, in this case, might be consistent with a previous report [5]. Furthermore, hepatic rSO2 was $34.1 \%$, which was relatively low compared to that in $43.2 \%$ of cerebral $\mathrm{rSO} 2$ in this case. However, the hepatic rSO2 ratio rapidly increased by ultrafiltration, and the degree of increase in hepatic rSO2 ratio was larger than that in cerebral rSO2 ratio during HD. Therefore, different from the relationship between cerebral and hepatic oxygenation without excess body fluid in HD patients [7], the deterioration in hepatic oxygenation may be larger than that in cerebral oxygenation under overhydrated status. In addition, hepatic oxygenation may be likely to improve compared to cerebral oxygenation according to the body fluid improvement induced by ultrafiltration. In this case, there might be a possibility to increase hepatic rSO2 beyond cerebral rSO2 in response to the further improvement in body fluid status, although hepatic rSO2 value was still low compared to that in cerebral rSO2 at second measurement after the improved CHF.

After his respiratory symptoms disappeared on the fourth hospital day, SpO2 dramatically improved at HD initiation even without oxygen inhalation. However, cerebral and hepatic rSO2 less improved compared to the SpO2 improvements. Previous studies reported no significant association between cerebral rSO2 and SpO2 in HD patients [10-12]. Therefore, the improvement of systemic oxygenation in the central circulation might be different from changes in tissue oxygenation in the microcirculation. That is, the improvement of microcirculation in tissues may be delayed compared to that of central circulation throughout the body fluid adjustment in HD patients. However, fluid status in the microcirculation could not be accurately evaluated and we cannot directly comment on these associations. Therefore, further studies are needed to investigate the mechanism of changes in systemic and tissue oxygenation in response to ultrafiltration in acute CHF.

\section{Conclusions}


We confirmed a remarkable increase in hepatic rSO2 ratio relative to cerebral rSO2 ratio under a CHF status during $\mathrm{HD}$, and these differences disappeared after the adjustment of the body fluid status.

\section{Additional Information \\ Disclosures}

Human subjects: Consent was obtained or waived by all participants in this study. Institutional Review Board of the Saitama Medical Center, Jichi Medical University, Japan issued approval RIN 15-104. This patient provided written informed consent to participate. The study was approved by the Institutional Review Board of the Saitama Medical Center, Jichi Medical University, Japan (RIN 15-104) and conformed to the provisions of the Declaration of Helsinki (as revised in Tokyo in 2004). Conflicts of interest: In compliance with the ICMJE uniform disclosure form, all authors declare the following: Payment/services info: All authors have declared that no financial support was received from any organization for the submitted work. Financial relationships: All authors have declared that they have no financial relationships at present or within the previous three years with any organizations that might have an interest in the submitted work. Other relationships: All authors have declared that there are no other relationships or activities that could appear to have influenced the submitted work.

\section{Acknowledgements}

We thank the study participants, and the staff members of the dialysis center at our hospital. We would like to thank Editage (www.editage.com) for English language editing. This work was supported by a grant from the Japanese Association of Dialysis Physicians (JADP grant 2017-9), a grant from the Kidney Foundation, Japan (JKFB 17-4), and Japan Society for the Promotion of Science KAKENHI under grant no. JP20K11534 to S.O.

\section{References}

1. Bello AK, Alrukhaimi M, Ashuntantang GA, et al.: Complications of chronic kidney disease: current state, knowledge gaps, and strategy for action. Kidney Int Suppl. 2017, 7:122-9. 10.1016/j.kisu.2017.07.007

2. Nitta K, Goto S, Masakane I, et al.: Annual dialysis data report 2018, JSDT renal data registry: survey methods, facility data, incidence, prevalence, and mortality. Renal Replace Ther. 2020, 6:41. 10.4009/jsdt.52.679

3. Wizemann V, Wabel P, Chamney P, et al.: The mortality risk of overhydration in haemodialysis patients . Nephrol Dial Transplant. 2009, 24:1574-9. 10.1093/ndt/gfn707

4. Ohashi Y, Sakai K, Hase H, et al.: Dry weight targeting: the art and science of conventional hemodialysis . Semin Dial. 2018, 31:551-6. 10.1111/sdi.12721

5. Minato S, Ookawara S, Ito K, et al.: Continuous monitoring of changes in cerebral oxygenation during hemodialysis in a patient with acute congestive heart failure. J Artif Organs. 2020, 23:292-5. 10.1007/s10047-019-01150-2

6. Hoshino T, Ookawara S, Goto S, et al.: Evaluation of cerebral oxygenation in patients undergoing long-term hemodialysis. Nephron Clin Pract. 2014, 126:57-61. 10.1159/000358432

7. Ookawara S, Ito K, Ueda Y, et al.: Differences in tissue oxygenation and changes in total hemoglobin signal strength in the brain, liver, and lower-limb muscle during hemodialysis. J Artif Organs. 2018, 21:86-93. 10.1007/s10047-017-0978-1

8. Madsen PL, Nielsen HB, Christiansen P: Well-being and cerebral oxygen saturation during acute heart failure in humans. Clin Physiol. 2000, 20:158-64. 10.1046/j.1365-2281.2000.00241.x

9. Hogan CJ, Ward KR, Pittman RC, Kontos MC, Thacker LR: Impact of congestive heart failure treatment on peripheral microvascular tissue oxygenation. Congest Heart Fail. 2011, 17:294-302. 10.1111/j.17517133.2011.00225.x

10. Ito K, Ookawara S, Ueda Y, et al.: Factors affecting cerebral oxygenation in hemodialysis patients: cerebral oxygenation associates with $\mathrm{pH}$, hemodialysis duration, serum albumin concentration, and diabetes mellitus. PLoS One. 2015, 10:0117474. 10.1371/journal.pone.0117474

11. Valerianova A, Lachmanova J, Kovarova T, Kmentova T, Bartkova M, Malik J: Factors responsible for cerebral hypoxia in hemodialysis population. Physiol Res. 2019, 68:651-8. 10.33549/physiolres.934064

12. Ookawara S, Ito K, Sasabuchi Y, et al.: Associations of cerebral oxygenation with hemoglobin levels evaluated by near-infrared spectroscopy in hemodialysis patients. PLoS One. 2020, 15:0236720. 10.1371/journal.pone.0236720 